ISSN : 2598-0521

\title{
TINGKAT PENDAPATAN, KONSUMSI, DAN TABUNGAN KELUARGA PENGHASIL DAN PEDAGANG KECAMBAH KACANG HIJAU DI KECAMATAN BELITANG II OKU TIMUR
}

\author{
AISAH \\ Sekolah Tinggi Ilmu Pertanian Belitang \\ Jl. Kampus Pertanian No.03 Belitang. OKU Timur. Sum-Sel Telp (0735) 4531056 \\ Agribisnis, STIPER Belitang, OKU Timur \\ Email : aisahputbel@gmail.com
}

\begin{abstract}
Mung bean sprouts are one of the sprouts / bean sprouts that are mostly used as food or consumption material in general, this is because the sprouts or bean sprouts from green beans contain a lot of gizi which is needed to facilitate defecation and to reduce obesity and increase fertility. Processing of green beans is expected to increase income which converts primary products into new products with higher economic value after going through the processing process, so it will be able to provide economic value because costs are incurred so that new higher prices are formed and the profits are greater than without going through the process processing. With this economic value, it causes an increase in the household income of farmers, which raises the potential for savings. The purpose of this study was to determine the level of income and business feasibility of mung bean sprouts in the East OKU Belitang II District, to determine the level of consumption and the level of savings of the green bean sprouts producer and trader in the East OKU Belitang II District. The results of the study concluded that the level of income obtained by the sprouts entrepreneur was Rp. 118,575 / process with the feasibility level of the sprouts business based on the ROI calculation of 56.03\%, BEP for Rp. 6,827 / Kg and BEP for Production of $0.87 \mathrm{~kg}$, Payback Period 3.57 and R / $\mathrm{C}$ of 1.56. The level of consumption of sprouts producers and traders is $\mathrm{Rp} 912,055$ / month. The level of savings for sprouts producers and traders is Rp 866,567 / month.
\end{abstract}

Keywords: Income, Consumption, Savings.

\section{PENDAHULUAN}

\section{A. Latar Belakang}

Di provinsi Sumatera Selatan banyak sekali bahan baku berupa kacang-kacangan salah satunya yaitu kacang hijau, rata-rata masyarakat masyarakat di Sumatera Selatan cukup kreatif dalam memanfaatkan salah satu hasil pertanian, antara lain pengolahan kacang hijau dimanfaatkan berbagai macam aneka makanan siap saji yaitu berupa bubur, aneka kue-kuean, dan lainnya. Selain dibuat sebagai bahan makanan berupa kue, kacang hijau juga dikonsumsi dalam bentuk kecambah. Kecambah kacang hijau adalah salah satu jenis kecambah/tauge yang paling banyak dijadikan bahan panagan atau bahan konsumsi pada umumnya, hal ini dikarenakan kecambah/tauge dari kacang hijau banyak mengandung gizi yang diperlukan untuk memperlancar buang air besar maupun untuk mengurangi kegemukan dan meningkatkan kesuburan.

Tujuan dari kegiatan tersebut adalah untuk meningkatkan pendapatan dan taraf hidup petani. Jadi salah satu sasaran pembangunan pertanian adalah untuk kesejahteraan keluarga petani, untuk mencapai keluarga sejahtera perlu adanya peningkatan pendapatan dan pengaturan penggunaan pendapatan. Pendapatan oleh rumah tangga keluarga digunakan untuk membiayai pengeluaran konsumsi mereka, sedangkan jika ada peningkatan pendapatan atau ada sisa dari pendapatan setelah dikonsumsi, maka akan menimbulkan pilihan oaring atau rumah tangga untuk melakukan tabungan (saving) dan biasanya sisa pendapatan yang tidak dikonsumsikan atau konsumsi yang ditunda ini di tabung. Pendapatan, pengeluaran dan tabungan memiliki hubungan yang sangat erat satu dengan yang lain.

Pengolahan kacang hijau duharapkan adanya peningkatan pendapatan yang mengubah produk primer menjadi produk baru yang lebih tinggi nilai ekonominya setelah melalui proses pengolahan, maka akan dapat memberikan nilai ekonomis karena dikeluarkannya biaya-biaya sehingga terbentuk harga baru yang lebih tinggi dan keuntungannya lebih besar dibandingkan tanpa melalui proses pengolahan. Dengan adanya nilai ekonomis tersebut menyebabkan bertambahnya pendapatan rumah tangga petani sehingga menimbulkan potensi tabungan.

\section{B. Rumusan Masalah}

1. Berapa tingkat pendapatan dan kelayakan usaha kecambah kacang hijau di Kecamatan Belitang II OKU Timur? 
2. Berapa tingkat konsumsi keluarga penghasil dan pedagang kecambah kacang hijau di Kecamatan Belitang II OKU Timur?

3. Berapa tingkat tabungan keluarga penghasil dan pedagang kecambah kacang hijau di Kecamatan Belitang II OKU Timur?

\section{Tujuan dan Kegunaan}

1. Untuk mengetahui tingkat pendapatan dan kelayakan usaha kacambah kacang hijau di Kecamatan Belitang II OKU Timur.

2. Untuk mengetahui tingkat konsumsi keluarga penghasil dan pedagang kecambah kacang hijau di Kecamatan Belitang II OKU Timur.

3. Untuk mengetahui tingkat tabungan keluarga penghasil dan pedagang kecambah kacang hijau di Kecamatan Belitang II OKU Timur.

D. Hipotesis

1. Bahwa pendapatan usaha kecambah kacang hijau di Kecamatan Belitang II OKU Timur memberikan keuntungan dan usaha ini layak untuk dikembangkan.

2. Bahwa penghasil dan pedagang kecambah kacang hijau di Kecamatan Belitang II OKU Timur dapat memenuhi kebutuhan konsumsi keluarga.

3. Bahwa konsumsi keluarga penghasil dan pedagang kecambah kacang hijau di Kecamatan Belitang II OKU Timur lebih kecil dibandingkan pendapatan sehingga memunculkan tabungan.

\section{METODOLOGI PELAKSANAAN}

\section{A. Tempat dan Waktu}

Penelitian ini telah dilaksanakan di Kecamatan belitang II OKU Timur. Penentuan lokasi secara purposive (sengaja) dengan pertimbangan terdapat pada usaha kecambah kacang hijau.

B. Metode Penelitian dan Penarikan Contoh Metode yang digunakan dalam penelitian ini adalah studi kasus (case study), karena studi kasus merupakan penelitian tentang status subjek penelitian yang berkenaan dengan suatu fase spesifik atau khas dari keseluruhan. Metode penarikan conroh yang digunakan adalah metode purposive (sengaja), dengan mengambil sampel 10 dari 10 jumlah populasi.

\section{Metode Pengumpulan Data}

Metode pengumpulan data dalam penelitian ini terdiri dari data primer dan data skunder. Data primer yang dikumpulkan adalah mengenai identitas responden dan keluarga, tingkat pendidikan responden dan keluarga pengusaha kecambah kacang hijau, biaya yang dikeluarkan selama proses produksi serta data-data penunjang lainnya. Sedangkan data skunder diperoleh dari lembaga-lembaga yang terkait dengan penelitian yang meliputi keadaan umum daerah, kedaan umum pengusaha kecambah kacang hijau, serta data lain yang dianggap perlu.

D. Metode Pengolahan Data

Metode pengolahan data yang akan digunakan dalam penelitian yaiitu data primer yang berhasil dikumpulkan yang ditabulasikan dan dianalisis secara deskriftif. Untuk mengetahui berapa besar pendapatan pengusaha dalam usaha kecambah kacang hijau.

Untuk mengetahui kelayakan usaha kacambah kacang hijau di Kecamatan Belitang II OKU Timur duguankan rumus sebagai berikut :

1. Untuk mengetahui jumlah biaya produksi digunakan rumus :

$\mathrm{TC}=\mathrm{FC}+\mathrm{VC}$

Keterangan :

$\mathrm{TC}=$ Total biaya $(\mathrm{Rp} /$ proses produksi $)$

$\mathrm{FC}=$ Baiay tetap $(\mathrm{Rp} /$ proses produksi $)$

$\mathrm{VC}=$ Biaya Variabel (Rp/proses produksi)

2. Untiuk mengetahui jumlah penerimaan digunakan rumus :

$\mathrm{TR}=\mathrm{P} \times \mathrm{Y}$

Keterangan :

$\mathrm{TR}=$ Total penerimaan $(\mathrm{Rp} /$ proses produksi)

$\mathrm{P}=\operatorname{Harga}(\mathrm{Rp} / \mathrm{Kg})$

$\mathrm{Y}=$ Jumlah produksi $(\mathrm{Kg})$

3. Untuk mengetahui pendapatan digunakan rumus :

$\mathrm{I}=\mathrm{TR}-\mathrm{TC}$

Keterangan :

$\mathrm{I}=$ Pendapatan $(\mathrm{Rp} /$ prosesproduksi)

$\mathrm{TR}=$ Total penerimaan $(\mathrm{Rp} /$ proses produksi)

$\mathrm{TC}=$ Total biaya $(\mathrm{Rp} /$ proses produksi $)$

4. $\mathrm{S}=\mathrm{I}-\mathrm{C}$

Keterangan :

$\mathrm{S}=$ Tabungan $(\mathrm{Rp} / \mathrm{bulan})$

$\mathrm{I}=$ Pendapatan (Rp/bulan)

$\mathrm{C}=$ Konsumsi $(\mathrm{Rp} / \mathrm{bulan})$

5. Untuk mengetahui kemampuan modal yang diinvestasikan untuk memberikan keuntungan bagi pengusaha kecambah kacang hijau menggunakan rumus : 
ISSN : 2598-0521

ROI (Return On Investment) $=\quad \mathrm{X}$ $100 \%$

TC

Keterangan :

$\mathrm{I}=$ Pendapatan $(\mathrm{Rp} /$ proses produksi $)$

$\mathrm{TC}=$ Total biaya $(\mathrm{Rp} /$ proses produksi $)$

6. Untuk mengetahui nilai titik impas (Break Event Ponit) di mana usaha tersebut tidak untung dan tidak rugi dapat digunakan rumus :

BEP Harga $=\frac{\mathrm{TC}}{\mathrm{Y}}$

BEP Produksi $=\frac{\mathrm{FC}}{\mathrm{P}-\mathrm{AVC}}$

Keterangan :

$\mathrm{TC}=$ Total Biaya $(\mathrm{Rp} /$ proses produksi $)$

$\mathrm{Y}=$ Jumlah Produksi $(\mathrm{Kg})$

$\mathrm{FC}=$ Biaya Tetap (Rp/proses produksi)

$\mathrm{P}=$ Harga $(\mathrm{Rp} / \mathrm{Kg})$

$\mathrm{AVC}=$ Biaya Variabel per unit

7. Payback Period (PBP) / Jangka Balik

Pokok dinyatakan dengan menggunakan rumus :

$\mathrm{JBP}=\frac{\mathrm{TC}}{\mathrm{I}} \times 2$ hari

Keterangan :

$\mathrm{TC}=$ Total Biaya $(\mathrm{Rp} /$ proses produksi $)$

$\mathrm{I}=$ Pendapatan $(\mathrm{Rp} /$ proses produksi $)$

8. Untuk menghitung keuntungan usaha kecambah kacang hijau menggunakan rumus:

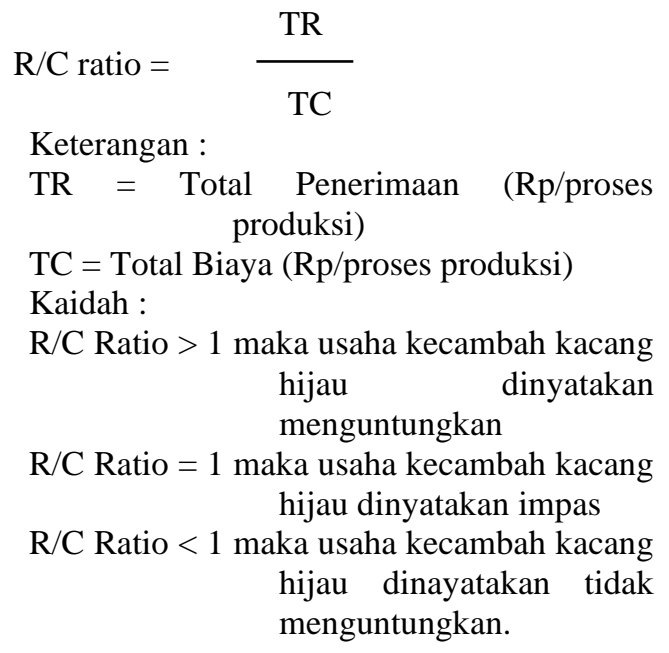

\section{PEMbahasAN}

\section{A. Potensi Usaha Kecambah Kacang Hijau di Kecamatan Belitang II OKU Timur.}

Kabupaten OKU Timur yang dikenal sebagai daerah lumbung pangan karena merupakan salah satu daerah penghasil beras yang mampu memberikan sumbangsih ketersediaan pangan nasional. Di Kecamatan Belitang II mata pencahariannya beragam mulai dari petani pedagang, PNS dan pengusaha, salah satunya adalah produksi kecambah kacang hijau. Pada umumnya kecambah kacang hijau ini sudah lama dikenal oleh kalangan masyarakat, tetapi masyarakat itu sendiri belum banyak yang mengembangkan usaha kecambah kacang hijau, karena permintaan dari masyarakat belum begitu banayak. Sehingga masyarakat belum berminat untuk memproduksi usaha kecambah kacang hijau.

Pada tahun 1999 permintaan kecambah kacang hijau mulai meningkat, dan dari itulah beberapa penduduk di Kecamatan Belitang II OKU Timur mulai tertarik untuk mengembangkan usaha kecambah kacang hijau. Menurut orang yang mengusahakan kecambah kacang hijau di Kecamatan Belitang II OKU Timur mengungkapkan bahwa dengan adanya usaha kecambah kacang hijau maka pengusaha kecambah kacang hijau dapat meningkat taraf hidup masyarakat.

Usaha pembuatan kecambah kacang hijau ini dalam melakukan produksi rata-rata mencapai 31 $\mathrm{Kg} /$ proses kecambah kacang hijau. Usaha kecambah kacang hijau ini selain dari permintaan hari-hari biasa, juga sering mendapatkan pesanan pada saat orang punya hajatan, di Kecamatan Belitang II OKU Timur mempunyai potensi dalam produksi kecambah kacang hijau dan mempunyai prospek usaha yang sangat menjanjikan. Sebenarnya usaha pembuatan kecambah kacang hijau ini dapat dikembangkan di kecamatan lain selain di Kecamatan Belitang II yang penting ada niat dan usaha dari seseorang itu sendiri yang ingin menjadi pengusaha kecambah kacang hijau.

\section{B. Analisis Usaha Kecambah Kacang Hijau 1. Biaya Produksi}

Biaya produksi adalah biaya yang harus dikeluarkan oleh pengusaha utuk dapat menghsilkan output. Biaya pembuatan kecambah kacang hijau meliputi biaya tetap (biaya penyusutan alat, dan sewa tempat) dan biaya variable (kacang hijau, plastic, HOK). Rata-rata biaya tetap yang dikeluarkan oleh setiap pengusaha kecambah kacang hijau sebesar Rp 3.419/proses produksi. Jumlah tersebut merupakan akumulasi dari biaya sewa lahan Rp 2.805,56/proses produksi. Biaya penyusutan alat bervariasi ini disebabkan karena mutu alat yang berbeda, intensitas pemakaian, umur alat dan pemeliharaan alat tersebut, 
alat-alat tersebut terdiri dari bak besar, rinjing (bakul), timbangan, tampah, keruntung, gayung. Rata-rata penyusutan alat mencapai Rp 613/proses produksi, sedangkan rata-rata biaya variable sebesar
Rp 208.207/proses produksi. Dari penjumlahan biaya tetap dan biaya variable maka akan diperoleh biaya produksi sebesar Rp 211.625/proses produksi.

Tabel 1. Biaya produksi yang dikeluarkan oleh usaha kecambah kacang hijau

\begin{tabular}{|c|c|c|c|c|}
\hline No & Responden & Biaya Tetap & Biaya Variabel & Jumlah (Rp/proses) \\
\hline 1 & 1 & 3.402 & 279.890 & 283.292 \\
\hline 2 & 2 & 3.061 & 234.857 & 237.918 \\
\hline 3 & 3 & 3.456 & 195.057 & 198.513 \\
\hline 4 & 4 & 3.374 & 202.427 & 205.800 \\
\hline 5 & 5 & 4.012 & 138.213 & 142.225 \\
\hline 6 & 6 & 3.387 & 137.797 & 141.148 \\
\hline 7 & 7 & 3.686 & 128.057 & 131.743 \\
\hline 8 & 8 & 3.391 & 243.440 & 246.831 \\
\hline 9 & 9 & 3.023 & 270.020 & 273.043 \\
\hline \multirow[t]{3}{*}{10} & 10 & 3.393 & 252.310 & 255.703 \\
\hline & Jumlah & 34.185 & 2.082 .067 & 2.116 .252 \\
\hline & Rata-rata & 3.419 & 208.207 & 211.625 \\
\hline
\end{tabular}

Sumber : Olahan Data Primer, tahun 2018.

\section{Penerimaan}

Penerimaan memiliki unsure dasar produktifitas (pada agribisnis) atau rendemen (pada agroindustri), disamping juga unsure harga sebagai pembentuk nilai. Secara perdefenisi revenue sama dengan produksi dikali harga (harga persatuan fisik). Produksi adalah suatu proses pendayagunaan segala sumber yang tersedia untuk mewujudkan hasil yang terjamin kualitas dan kuantitasnya, terkelola dengan baik sehingga merupakan komoditi yang diperdagangkan. Produksi yang dihasilkan dari usaha ini adalah kecambah kacang hijau. Adapun rata-rata produksi kecambah kacang hijau sebanyak 31 $\mathrm{Kg} /$ prose dikalikan dengan harga kecambah kacang hijau sebesar Rp $10.650 \mathrm{Kg} /$ proses maka akan diperoleh penerimaan sebesar Rp 330.200/proses.

Tabel 2. Penerimaan usaha kecambah kacang hijau di Kecamatan Belitang II Ogan Komering Ulu Timur.

\begin{tabular}{|c|c|c|c|c|c|}
\hline No & Resp & Nama Barang & Unit & Harga $(\mathrm{Rp} / \mathrm{kg})$ & Jumlah (Rp/proses) \\
\hline 1 & 1 & Kecambah & 40 & 11.000 & 440.000 \\
\hline 2 & 2 & Kecambah & 36 & 10.500 & 378.000 \\
\hline 3 & 3 & Kecambah & 30 & 11.000 & 330.000 \\
\hline 4 & 4 & Kecambah & 30 & 11.000 & 330.000 \\
\hline 5 & 5 & Kecambah & 20 & 10.000 & 200.000 \\
\hline 6 & 6 & Kecambah & 20 & 10.000 & 200.000 \\
\hline 7 & 7 & Kecambah & 20 & 10.500 & 210.000 \\
\hline 8 & 8 & Kecambah & 36 & 11.000 & 396.000 \\
\hline 9 & 9 & Kecambah & 40 & 11.000 & 440.000 \\
\hline 10 & 10 & Kecambah & 36 & 10.500 & 378.000 \\
\hline \multicolumn{3}{|c|}{ Jumlah } & 308 & 106.500 & 3.302 .000 \\
\hline \multicolumn{3}{|c|}{ Rata-rata } & 31 & 10.650 & 330.200 \\
\hline \multicolumn{3}{|c|}{ Sumber : Olahan data primer,tahun 2018.} & \multicolumn{3}{|c|}{$\begin{array}{l}\text { merupakan nilai bersih yang diterima oleh responden } \\
\text { dari hasil total usaha }\end{array}$} \\
\hline unit & $\begin{array}{l}\text { ndapat } \\
\text { yang }\end{array}$ & $\begin{array}{l}\text { endapatan } \\
\text { l adalah sama dengan jumlah } \\
\text { dikalikan harga output per }\end{array}$ & \multicolumn{3}{|c|}{$\begin{array}{l}\text { agribisnis yaitu jumlah penerimaan usaha agribisnis } \\
\text { dikurangi dengan total biaya usaha agribisnis terdiri } \\
\text { dari biaya tetap dan biaya variable. }\end{array}$} \\
\hline \multicolumn{3}{|c|}{$\begin{array}{l}\text { unit. Biasanya semakin tinggi tingkat pendapatan, } \\
\text { tingkat konsumsi makin tinggi, karena tingkat } \\
\text { pendapatan meningkat. Pendapatan usaha agribisnis }\end{array}$} & \multicolumn{3}{|c|}{$\begin{array}{l}\text { Pendapatan yang diterima } \\
\text { ah kacang hijau dalam satu kali proses } \\
\text { i sebesar Rp 118.575. }\end{array}$} \\
\hline
\end{tabular}


ISSN : 2598-0521

pendapatan diperoleh dengan cara mengurangkan nilai penerimaan sebesar Rp 330.200/proses dengan biaya produksi sebesar $\mathrm{Rp} 211.625 /$ proses yang sudah dikeluarkan.

Tabel 3. Pendapatan usaha kecambah kacang hijau di Kecamatan Belitang II Ogan Komering Ulu Timur.

\begin{tabular}{|c|c|c|c|c|c|}
\hline \multirow[t]{2}{*}{ No } & \multirow[t]{2}{*}{ Resp } & \multirow{2}{*}{$\frac{\text { Penerimaan }}{\text { (Rp/proses ) }}$} & Biaya Produksi & Pendapatan & Pendapatan \\
\hline & & & (Rp/proses) & (Rp/prose) & ( Rp/bulan ) \\
\hline 1 & 1 & 440.000 & 283.292 & 156.708 & 2.350.620 \\
\hline 2 & 2 & 378.000 & 237.918 & 140.082 & 2. 101.229 \\
\hline 3 & 3 & 330.000 & 198.513 & 131.487 & 1.972 .312 \\
\hline 4 & 4 & 330.000 & 205.800 & 124.200 & 1. 862.994 \\
\hline 5 & 5 & 200.000 & 142.225 & 57.775 & 866.622 \\
\hline 6 & 6 & 200.000 & 141.184 & 58.816 & 882.240 \\
\hline 7 & 7 & 210.000 & 131.743 & 78.257 & 1. 173.856 \\
\hline 8 & 8 & 396.000 & 246.831 & 149.169 & 2. 237.540 \\
\hline 9 & 9 & 440.000 & 273.043 & 166.957 & 2. 504.351 \\
\hline 10 & 10 & 378.000 & 255.703 & 122.297 & 1. 834.560 \\
\hline \multicolumn{2}{|c|}{ Jumlah } & 3.302 .000 & 2.116 .252 & 1.185 .748 & 17.786 .223 \\
\hline \multicolumn{2}{|c|}{ Rata-rata } & 330.200 & 211.625 & 118.575 & 1.778 .622 \\
\hline
\end{tabular}

Sumber : Olahan data primer, tahun 2018.

\section{Konsumsi}

Rata-rata konsumsi rumah tangga responden usaha kecambah kacang hijau sebesar Rp 912.055/bulan. Jumlah tersebut berasal dari konsumsi pangan sebesar Rp 495.455/bulan, sedangkan untuk konsumsi non pangan sebesar Rp 416.600/bulan dapat dilihat pada table berikut :

Tabel 4. Konsumsi usaha kecambah kacang hijau di Kecamatan Belitang II Ogan Komering Ulu Timur.

\begin{tabular}{|c|c|c|c|c|}
\hline No & Resp & $\begin{array}{l}\text { Konsumsi Pangan } \\
\text { (Rp/bulan) }\end{array}$ & $\begin{array}{l}\text { Konsumsi Non Pangan } \\
\text { (Rp/bulan) }\end{array}$ & $\begin{array}{l}\text { Total Konsumsi } \\
\text { (Rp/bulan) }\end{array}$ \\
\hline 1 & 1 & 480.500 & 462.000 & 942.500 \\
\hline 2 & 2 & 443.300 & 310.000 & 753.300 \\
\hline 3 & 3 & 480.750 & 323.000 & 803.750 \\
\hline 4 & 4 & 429.750 & 342.500 & 772.250 \\
\hline 5 & 5 & 459.600 & 335.000 & 794.600 \\
\hline 6 & 6 & 478.750 & 402.000 & 880.750 \\
\hline 7 & 7 & 545.650 & 244.000 & 789.650 \\
\hline 8 & 8 & 468.250 & 492.000 & 960.250 \\
\hline 9 & 9 & 553.300 & 754.000 & 1.307 .300 \\
\hline 10 & 10 & 614.700 & 501.500 & 1.116 .200 \\
\hline \multicolumn{2}{|c|}{ Jumlah } & 4.954 .550 & 4.166 .000 & 9.120 .550 \\
\hline \multicolumn{2}{|c|}{ Rata-rata } & 495.455 & 416.600 & 912.055 \\
\hline \multicolumn{5}{|c|}{ Sumber : Olahan data primer, tahun 2018.} \\
\hline \multicolumn{3}{|c|}{$\begin{array}{l}\text { Rata-rata tabungan responden pada usaha } \\
\text { kecambah kacang hijau sebesar Rp } 866.567 / \text { bulan. } \\
\text { Hasil ini didapat dari pendapatan total sebesar Rp }\end{array}$} & 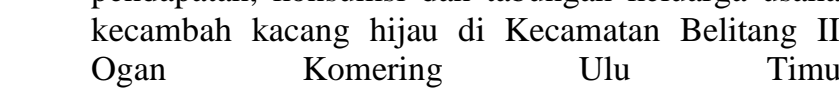 & $\begin{array}{l}\text { 1.778.622/bulan dikurangi konsumsi total sebesar Rp } \\
912.055 / \text { bulan. Table } 5 \text { menjelaskan tingkat } \\
\text { pendapan, konsumsi dan tabungan keluarga usaha }\end{array}$ \\
\hline \multicolumn{5}{|c|}{ Tabel 5. Tabungan usaha kecambah kacang hijau di Kecamatan Belitang II Ogan Komering Ulu Timur. } \\
\hline No & Resp & Pendapatan total (Rp/bulan) & Konsumsi Total (Rp/bulan) & Tabungan (Rp/bulan) \\
\hline 1 & 1 & 2.350 .620 & 942.500 & 1.408 .120 \\
\hline 2 & 2 & 2.101 .229 & 753.300 & 1.347 .929 \\
\hline 3 & 3 & 1.972 .312 & 803.750 & 1.168 .562 \\
\hline
\end{tabular}


ISSN : 2598-0521

\begin{tabular}{rrrrr}
\hline 4 & 4 & 1.862 .994 & 772.250 & 1.090 .744 \\
5 & 5 & 866.622 & 794.600 & 72.022 \\
6 & 6 & 882.240 & 880.750 & 1.490 \\
7 & 7 & 1.173 .856 & 789.650 & 384.206 \\
8 & 8 & 2.237 .540 & 960.250 & 1.277 .290 \\
9 & 9 & 2.504 .351 & 1.307 .300 & 1.197 .051 \\
10 & 10 & 1.834 .460 & 1.116 .200 & 718.260 \\
\hline \multicolumn{2}{c}{ Jumlah } & 17.786 .223 & 9.120 .550 & 8.665 .673 \\
\hline \multicolumn{2}{c}{ Rata-rata } & 1.778 .622 & 912.055 & 866.567 \\
\hline
\end{tabular}

Sumber : Olahan data primer, tahun 2018.

Tabel 6. Rata-rata ROI, BEP Harga, BEP Produksi, Payback Period, R/C Ratio Usaha Kecambah Kacang Hijau di Kecamatan Belitang II Ogan Komering Ulu Timur.

\begin{tabular}{clcr}
\hline No & \multicolumn{1}{c}{ Uraian } & Satuan & Jumlah \\
\hline 1 & ROI & $\%$ & 56,03 \\
2 & BEP Harga & Rp & 6.827 \\
3 & BEP Produksi & Kg & 0,87 \\
4 & Payback Period & Periode / Hari & 3,57 \\
5 & R/C Ratio & & 1,56 \\
\hline
\end{tabular}

Sumber : Olahan data primer, tahun 2018.

\section{ROI}

ROI (Return On Invesmen) atau efisiensi penggunaan modal merupakan analisis untuk mengetahui keuntungan usaha (input) berkaitan dengan modal yang telah dikeluarkan (output) besar kecilnya nilai ROI ditentukan oleh keuntungan yang diperoleh dari perputaran modal.

Perbandingan antara pendapatan sebesar Rp 118.575/proses dengan biaya produksi sebesar Rp 211.625/proses yang dikeluarkan selama usaha kecambah kacang hijau sebesar $56.03 \%$, artinya setiap pengeluaran modal usaha akan menghasilkan keuntungan sebesar $56.03 \%$.

\section{BEP (Harga dan Produksi)}

a. BEP Harga

BEP Harga menggambarkan harga terendah dari produk yang dihasilkan. Apabila harga pasaran ditingkat petani lebih rendah dari harga BEP, maka usahatani akan mengalami kerugian. Harga BEP merupakan harga pokok atau harga dasar untuk mengembalikan modal, maka agar usahatani untung petani harus menjual produknya di atas harga dasar.

BEP Harga merupakan pembagian antara jumlah dari biaya produksi sebesar Rp 211.625/proses, sedangkan jumlah dari rata-rata produksi sebesar $31 \mathrm{Kg}$ sehingga jumlah produksinya sebesar $\mathrm{Rp}$ $6.827 / \mathrm{Kg}$, artinya bahwa untuk BEP harga kecambah kacang hijau sebesar Rp 6.827/Kg, sehingga produsen tidak mengalami untung atau rugi.

b. BEP Produksi
Mengambarkan produksi minimal yang harus dihasilkan dalam usahatani agar tidak mengalami kerugian.

BEP Produksi merupakan pembagian antara jumlah dari biaya tetap dibagi dengan harga dan biaya variable perunit. Jumlah dari biaya tetap sebesar Rp 3.419, harga kecambah Rp $10.650 / \mathrm{Kg}$, biaya variable perunit $\mathrm{Rp}$ 6.716/proses, sehingga diperoleh BEP Produksi sebesar $0,87 \mathrm{Kg}$.

\section{Payback Period (PP)}

Payback Period (PP) merupakan jangka balik pokok atas modal yang dikeluarkan pada usaha kecambah kacang hijau. Diperoleh dari hasil perbandingan antara total biaya sebesar $\mathrm{Rp}$ 211.625/proses dengan pendapatan sebesar $\mathrm{Rp}$ 118.575/proses sehingga mendapatkan 3,57 yang berarti bahwa usaha tersebut akan balik pokok pada 4 periode atau 8 hari.

\section{R/C Ratio}

R/C Ratio yaitu suatu analisis untuk mengetahui untung rugi dari suatu usaha dengan membandingkan antara penerimaan dan biaya produksi yang telah dikeluarkan. R/C Ratio merupakan perbandingan antara total penerimaan sebesar Rp 330.200/proses, sedangkan jumlah biaya produksi Rp 211.625/proses, sehingga diperoleh nilai dari R/C Ratio sebesar 1,56 yang berarti bahwa dalam setiap satu rupiahnya biaya produksi yang dikeluarkan akan memperoleh penerimaan sebesar 1,56 . 
ISSN : 2598-0521

\section{Kesimpulan dan Saran}

\section{A. Kesimpulan}

Kesimpulan yang dapat diambil adalah sebagai berikut :

1. Tingkat pendapatan yang diperoleh pengusaha kecambah adalah Rp 118.575/proses dengan tingkat kelayakan usaha kecambah berdasarkan hasil perhitungan ROI sebesar $56.03 \%$, BEP Harga Rp 6.827/Kg dan BEP Produksi 0,87 Kg, Payback Period 3,57 dan R/C Ratio sebesar 1,56.

2. Tingkat konsumsi penghasil dan pedagang kecambah adalah sebesar Rp 912.055/bulan.

3. Tingkat tabungan penghasil dan pedagang kecambah adalah sebesar Rp 866.567/bulan.

\section{B. Saran}

Saran yang dapat diberikan adalah sebagai berikut :

1. Kepada penghasil dan pedagang kecambah diharapkan dapat membaca peluang pasar yang diminati oleh konsumen, sehingga dapat meningkat produksi dan pendapatan keluarga.

2. Perlu adanya diversifikasi lain dari usaha kecambah untuk memberikan inovasi produk kepada konsumen untuk menambah penganekaragaman produk.

\section{DAFTAR PUSTAKA}

Daniel, M. 2002 Pengantar Ekonomi Pertanian. PT Bumi Aksara. Jakarta.

Dunia Firdaus, A. 2008. Pengantar Akuntansi. Penerbit Fakultas Universitas Indonesia. Jakarta.

Ibrahim, Y. 2009. Studi Kelayakan Bisnis. PT. Rineka Cipta. Jakarta.

Kotler dan Keller, 2008. Manajemen Pemasaran. Penerbit Erlangga. Jakarta.
Manurung, M dan Rahardja, P. 2008. Pengantar Ilmu Ekonomi. Penerbit Fakultas Ekonomi Universitas Indonesia. Jakarta.

Purwono dan Hartono. 2005. Seri Agribisnis Kacang Hijau. Penebar Swadaya. Jakarta.

Rosydi, S. 2011. Pengantar Teori Ekonomi : Pendekatan Kepada Teori Ekonomi Mikro dan Makro. PT. Raja Grafindo Persada. Jakarta.

Soekartawi. 2002. Analisis Usaha Tani. Universitas Indonesia. Jakarta.

Soediyono, R. 2000. Pengantar Teori Ekonomi Makro. Penerbit Fakultas Ekonomi. Universitas Gajah Mada. Yogyakarta.

Sjarkowi, F dan Sufri, M. 2004. Manajemen Agribisnis. CV Baldad Grafiti Press. Palembang.

Sumardjo, Sulaksana dan Darmono. 2004. Teori dan Praktik Kemitraan Agribisnis. Penebar Swadaya. Jakarta.

Suratiyah, K. 2006. Ilmu Usaha Tani. Penebar Swadaya. Jakarta.

Tim Survei KHL. 2012. Laporan Bulanan Komponen Kebutuhan Hidup Layak Untuk Pekerja Lajang. Dinas Tenaga Kerja dan Transmigrasi OKU Timur.

Warintek, 2004. Kacang Hijau (Phaseolus radiates L.). Surabaya. 